\title{
Local Natural Medicine Wisdom and Medical Cosmetology
}

Somsri $\mathbf{W}^{*}$ and Wiwanitkit $\mathbf{V}$

Wiwanitkit House, Bangkhae, Bangkok, Thailand

*Corresponding author: Somsri W, Wiwanitkit House, Bangkhae, Bangkok, Thailand, Tel: 6624132436; Fax: 6624132436. Email: somsriwiwan@hotmail.com

Received date: Sep 7, 2015; Accepted date: Sep 28, 2015; Published Date: Oct 2, 2015

Copyright: (C) 2015 Somsri W, This is an open-access article distributed under the terms of the Creative Commons Attribution License, which permits unrestricted use, distribution, and reproduction in any medium, provided the original author and source are credited.

\section{Letter to Editor}

Dear editor, beautiful has been the topic of interest for a long time. Everyone like a beauty appearance and the cosmetology is the specific science for promotion of beauty. The medical cosmetology is widely practice at present. Many new advance cosmetic materials and techniques are available. Most of them are artificial and synthesized. Based on the concept of green technology and think earth at present, returning to the nature is the new concept [1]. Of several fields of medicine in the present day, natural medicine is the specific medicine with the closest relationship to nature. It is interesting that the use of natural medicine in medical cosmetology should be promoted. In fact, there are several local wisdoms regarding the beauty promotion and this should be further studied and researched in medical cosmetology. Several herbal medicine systems have been reintroduced for a few years [2]. As the local wisdom pass a long period of time, the safety and efficacy might be expected. However, there are several obstacles on using local natural medicine wisdom and medical cosmetology. Those problems include,
Lack of modern proofs on local wisdom cosmetic regimens

Slow and lack of modern quality control in preparation of classical natural product

Lack of legal control on manufacturer and distribution.

How to promote and redecorate the wisdom to reach the present fashion and modern trend is the topic for further research and development.

\section{References}

1. Harth W, Seikowski K, Hermes B, Gieler U (2008) Lifestyle drugs in medicine. Wien Med Wochenschr 158: 110-115.

2. Mosihuzzaman M (2012) Herbal medicine in healthcare-an overview. Nat Prod Commun Jun 7: 807-812. 